\title{
Reinterpreting the Apparent Rise of Diatoms Through a Diagenetic Lens
}

\author{
SOPHIE WESTACOTT ${ }^{1}$, NOAH J. PLANAVSKY ${ }^{1}$, \\ MINGYU ZHAO ${ }^{2}$ AND PINCELLI M. HULL ${ }^{1}$
}

\author{
${ }^{1}$ Yale University \\ ${ }^{2}$ University of Leeds \\ Presenting Author: sophie.westacott@yale.edu
}

The modern marine silica cycle is largely controlled by diatoms, whose ecological rise during the Cenozoic is believed to have lowered silica concentrations by up to two orders of magnitude. Diatoms' expansion in the Neogene has also been tied to the rise of grasslands and baleen whales, and to declining atmospheric $\mathrm{CO}_{2}$. The siliceous microfossil record indicates diatoms rose to their current level of ecological prominence largely in the last $\sim 20$ m.y., but silicon isotope evidence suggests modern-level surface seawater $\mathrm{Si}$ concentrations extend at least as far back $60 \mathrm{Ma}$, suggesting a much earlier diatom expansion. We used a diagenetic model and collated deep sea drill core data to explore the effect of changing bottom-water temperatures and deep sea sedimentation rates over the past 65 on the burial efficiency and preservation potential of biogenic silica. We find that taphonomy alone can account for much of the traditionally recognized $\sim 5-20 \mathrm{Ma}$ apparent increase in diatom abundance. It also may be account for the concurrent decrease in silicification observed in radiolarians and other silicifiers. Our results add to other evidence pushing back the timeline of the evolution of the modern silica cycle to before $20 \mathrm{Ma}$ and potentially considerably earlier. Our results also highlight which trends in Cenozoic diatom fossil abundance are likely primary, rather than diagenetic. 